Research Article

\title{
Effect of Temperature on the Mechanical Properties of Carbon Composites
}

\author{
Ali Anvari [ \\ Department of Mechanical and Aerospace Engineering, University of Missouri-Columbia, Columbia, MO, USA \\ Correspondence should be addressed to Ali Anvari; aabm9@mail.missouri.edu
}

Received 13 May 2020; Revised 1 July 2020; Accepted 3 July 2020; Published 24 July 2020

Academic Editor: Roberto Brighenti

Copyright (@) 2020 Ali Anvari. This is an open access article distributed under the Creative Commons Attribution License, which permits unrestricted use, distribution, and reproduction in any medium, provided the original work is properly cited.

\begin{abstract}
The purpose of this research is to investigate and analyze the effect of temperature on the mechanical properties of carbon composites, aluminum foam, and carbon nanotube reinforced aluminum foam. For this analysis, fatigue behavior of aluminum foam has been discussed, and interlaminar shear stress between single-walled carbon nanotube reinforced aluminum foam and multiwalled carbon nanotube reinforced aluminum foam has been compared. The comparison has shown that the interlaminar shear stress within the interface of single-walled carbon nanotube and aluminum foam is higher than that within the interface of multiwalled carbon nanotube and aluminum foam. Hence, the probability of stress concentration and crack initiation within the interface of single-walled carbon nanotube and aluminum foam is higher than that within the interface of multiwalled carbon nanotube and aluminum foam. Furthermore, thermal fatigue lives of different single-walled carbon nanotube reinforced matrix nanocomposites have been evaluated. Additionally, interaction between carbon and molten aluminum has been analyzed. Finally, a new relation for the thermal interlaminar shear stress intensity factor to predict the crack initiation sites on fiber/matrix interface has been introduced.
\end{abstract}

\section{Introduction}

Carbon nanotubes (CNTs) have been introduced by Lijima in 1991 for the first time [1]. Due to the excellent properties of CNT, nowadays its application is broad in many industries such as aerospace and automotive industries. Carbon nanotubes have great mechanical properties such as high tensile strength, high Young's modulus, and high aspect ratio which makes CNT one of the best materials for different applications. Furthermore, the electrical conductivity of CNT is high [2]. Hence, recently, for enhancing the knowledge regarding the CNTs, a few studies to further analyze the mechanics and forest synthesis of CNT have been published [3-6]. Additionally, for evaluating the effect of CNTs on the mechanical and/or thermal properties of composite materials, many studies have been provided [7-10].

There are many methods to produce the CNTs such as catalyst arrays, chemical vapor deposition, electric arc discharge, sonochemistry, laser ablation, and electrolysis. It is important to know that each of these production methods will result in different CNTs with different geometries because the diameter and the length of CNTs will be different with each of these production methods. The different geometries of CNT can have effects on its reactivity, failure mechanism, surface interaction, and mechanical properties. Therefore, it seems that, with different production methods, different CNTs with different properties can be expected [2].

The application of CNT is broad in many industries due to its multifunctional properties such as thermal management, enhanced stiffness, and improved toughness [11]. There are several methods to disperse the CNTs within the matrix. Among these methods, the most effective one is the chemical treatment with ultrasonication process [12].

CNTs are the crystalline shape of carbon. They have high aspect ratio due to the size of diameter which is a few nanometers and the size of length of it which is typically about a few microns. Furthermore, they offer high flexibility and high thermal conductivity. CNTs can be in the forms of 
multiwalled carbon nanotubes (MWCNTs) and singlewalled carbon nanotubes (SWCNTs) [12].

\subsection{Mechanical Properties, Geometries, and Failure} Mechanism. As it has been mentioned previously, the discovery of CNTs occurred in 1991. After the discovery of CNTs, their application started to increase due to the unique and important properties such as high strength, high modulus, high stiffness, electrical conductivity, etc. Compared to steel which is one of the most popular metals in different industries, CNTs offer higher Young's modulus and tensile strength. Young's modulus of steel is about $200 \mathrm{GPa}$, while Young's modulus of CNTs is around $1 \mathrm{TPa}$. The tensile strength of steel is about $505 \mathrm{MPa}$ while the tensile strength of CNTs is about $1163 \mathrm{GPa}$. Moreover, CNTs can be used in other applications such as energy storage devices, hydrogen storage media, sensors, and many more [13].

CNTs are composed of graphene layers rolled to form cylinders with fullerene caps. SWCNT has only one graphene sheet while MWCNT has several graphene sheets rolled over each other with the same axis. The geometries of CNTs could be in three states: 1 . armchair; 2 . zig-zag; and 3. chiral. CNT thickness is $0.34 \mathrm{~nm}$ which is equal to the thickness of graphene sheet, but the length and dimeter of the CNT can vary. In Figure 1, the three different geometries of CNTs are illustrated [13].

\section{Ranking of Unidirectional Fibers/Matrix Composites Based on Their Interlaminar Shear Stress}

The aim of this section of the study is to rank the unidirectional fibers/matrix composites based on the interlaminar shear stress existing between fibers and matrix due to thermal stress. Thermal stress induced in composites is one of the main issues in many applications such as space structures. In this section, by applying an analytical method, it is attempted to estimate the ranking of unidirectional fibers/matrix composites exposed to thermal stress based on their interlaminar shear stress between the fibers and matrix. The application of the results of this research is very broad. These results could be very advantageous in any industry using unidirectional fibers/matrix composites exposed to thermal stress such as aerospace automotive, etc.

Thermal stress is one of the main issues in application of composites in many applications such as aerospace industry. Space structures are exposed to thermal cycles that induce thermal stress in composite structures in space. In order to investigate this effect, numbers of studies have been performed by Funk and Sykes [14], Shin et al. [15], and Unigovski et al.[16]. The objectives of the mentioned studies were to understand the damage induced due to thermal cyclic exposures.

In 2012 [17], Park et al. have conducted an experiment to simulate the thermal cycling in Low Earth Orbit (LEO) environment and estimate the effect of that on Unidirectional Carbon Fiber/Epoxy Composite (UD CF/EP). UD CF/ EP material is one of the composite materials that is applied in aerospace structures such as satellites [17]. The objective of this experiment was to estimate the deterioration of UD $\mathrm{CF} / \mathrm{EP}$ mechanical properties in LEO due to thermal cycling exposure.

Additionally, in 2018 [18], the experimental results achieved by Park et al. [17] have been analyzed. The analysis of the experimental results had indicated that Interlaminar Shear Strength (ILSS), Flexural Strength (FS), and Flexural Modulus (FM) of UD CF/EP were decreasing as thermal cycles were increasing in LEO simulation experiment. Furthermore, based on the experimental results, it has been approximated that the deterioration of ILSS in UD CF/EP can be the main cause of fracture in UD CF/EP exposed to thermal stress.

Nevertheless, it appears that there is no study to rank the unidirectional fibers/matrix composites (UFMCs) based on their interlaminar shear stress (ILSs). In the presented study, by applying an analytical method, the amounts of ILSs in UFMCs are calculated. Based on the assumption which has been approved in 2018 [18], the higher the ILSs is, the higher the probability to cause the fracture within the UFMC becomes. Thus, the best UFMC in terms of minimum probability of fracture or more durability when exposed to thermal cycling is the one with the minimum ILSs. As a result, this calculation would contribute to ranking the UFMCs based on their minimum ILSs (higher durability or higher thermal fatigue life).

2.1. Interlaminar Shear Stress between the Fibers and Matrix Interfaces. In 2018 [18], a relation has been proposed to estimate the ILSs within the UFMCs interfaces between the fibers and matrix. This equation is indicated as follows:

$$
\text { ILSs }=\left(\alpha_{\mathrm{c}}-\alpha_{\mathrm{F}}\right) \cdot \Delta T \cdot G \text {. }
$$

In this part of the manuscript, equation (1) [18] is employed to estimate the maximum ILSs. Based on the results obtained in 2018 [18], deterioration of ILSS in UD $\mathrm{CF} / \mathrm{EP}$ seems to be the main cause of failure of this composite material which has been exposed to thermal cycling. Thus, in this section, it has been tried to establish a system to calculate the ILSs in common UFMC materials. This interpretation would verify that the risk of failure in UFMC is increased while ILSs is increased. Therefore, in this part of the article, ILSs in common UFMCs are calculated in order to rank them. It is important to notice that equation (1) is only valid in cases which fibers are impeded and constrained within the matrix.

In order to calculate the maximum ILSs (ILSs $s_{\max }$ ), it is enough to replace the shear modulus with maximum shear modulus in equation (1). Thus, equation (1) becomes

$$
\mathrm{ILSs}_{\max }=\left(\alpha_{\mathrm{c}}-\alpha_{\mathrm{F}}\right) \cdot \Delta T \cdot G_{\max } .
$$

In the equation (2), $\alpha_{\mathrm{c}}$ is the Coefficient of Thermal Expansion (CTE) of matrix in axial direction, $\alpha_{\mathrm{F}}$ is the CTE of fiber in axial direction, and $\Delta T$ is the difference between the stress-free or crack-free temperature of the UFMC and the environment temperature. Furthermore, $G_{\max }$ is the maximum shear modulus. It is important to notice that $G_{\max }$ 


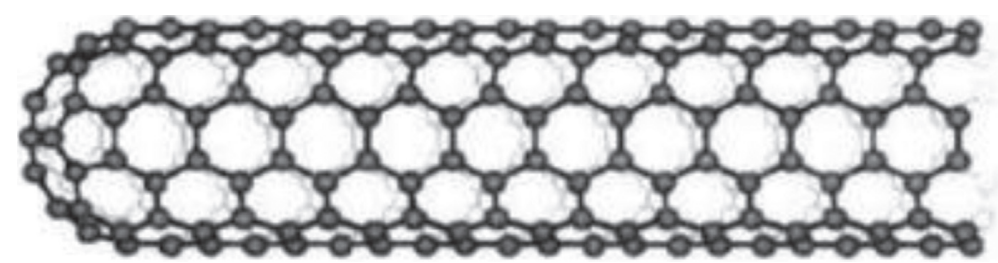

(a)

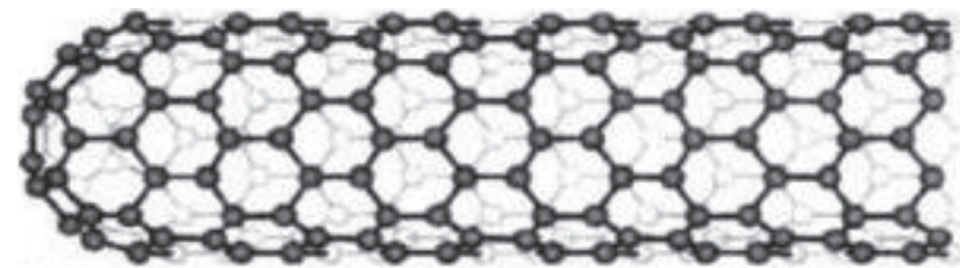

(b)

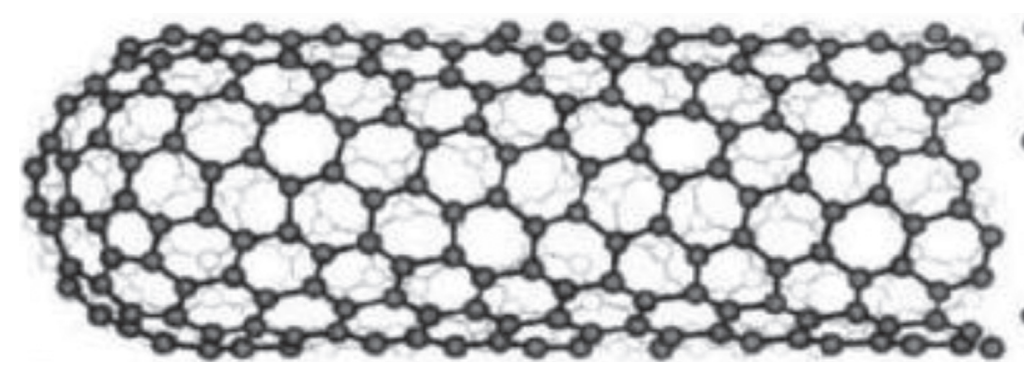

(c)
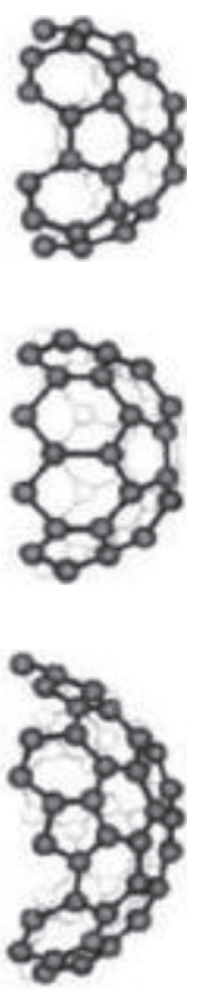

FIGURE 1: Different chiralities of CNTs: (a) armchair; (b) zig-zag; (c) chiral [13].

is determined by comparison between the shear modulus of matrix and fiber. The largest value of $G$ along the fibers' direction between the matrix and fiber needs to be identified and be substituted in equation (2), in order to obtain ILSs $s_{\max }$.

In Tables 1 and 2, there are lists of all common matrices and fibers used to develop UFMCs, respectively. In the Results and Discussion section, with applying equation (2), ILSs $_{\max }$ of possible UFMCs exposed to thermal stress has been calculated.

2.2. Results and Discussion. In Table 3 , ILSs $\mathrm{Imax}_{\max }$ for 54 types of UFMCs are indicated as a function of $\Delta T$. In evaluation of the ILSs $s_{\max }$ for ranking the composite materials, the amount of $\Delta T$ is not required because it is assumed to be of the same value for all the materials and is constant for all of them. In order to use the values of ILSs $s_{\max }$ in Table 3, it is enough to have this knowledge that, based on the results obtained in 2018 [18], ILSs could be the main cause of fracture and/or de-bonding within the UFMCs. Consequently, as the value of ILSs increases, the probability of de-bonding or breaking bonds between fibers and matrix increases. This phenomenon will lead to crack initiation, propagation, and ultimately fracture within the UFMC.

Based on equation (2), as the difference between the CTEs of fibers and matrix increases, ILSs $s_{\max }$ increases. Furthermore, as the shear modulus increases, ILSs $\mathrm{max}_{\max }$ increases. Thus, ILSs $s_{\max }$ is proportional to the difference of
TABle 1: Axial shear modulus $\left(G_{\mathrm{c}}\right)$ and axial CTE $\left(\alpha_{\mathrm{c}}\right)$ of common matrix materials.

\begin{tabular}{lccc}
\hline No. & Matrix name & $\alpha_{\mathrm{c}}\left(10^{-6} /{ }^{\circ} \mathrm{C}\right)$ & $G_{\mathrm{c}}(\mathrm{GPa})$ \\
\hline 1 & 934 epoxy & $43.92[19]$ & $1.590[19]$ \\
2 & 5208 epoxy & $43.92[19]$ & $1.590[19]$ \\
3 & 930 epoxy & $43.92[19]$ & $1.590[19]$ \\
4 & CE339 epoxy & $63.36[19]$ & $1.590[19]$ \\
5 & PMR15 polyimide & $36.00[19]$ & $1.310[19]$ \\
6 & 2024 aluminum & $23.22[19]$ & $27.58[19]$ \\
7 & Borosilicate glass & $3.240[19]$ & $26.20[19]$ \\
8 & Al99.5 & $22.60[20]$ & $26.00[20]$ \\
9 & 6061 aluminum & $23.60[21]$ & $26.00[21]$ \\
10 & AZ91D Mg & $28.50[21]$ & $16.60[21]$ \\
\hline
\end{tabular}

CTEs between fibers and matrix, and maximum shear modulus between fibers and matrix in axial direction.

It seems that the mismatch of CTEs between fibers and matrix is a great cause of failure, de-bonding, or fracture between those. The reason behind is that the axial CTE of the matrix is a positive value and the axial CTE of fiber, in most cases, is a negative value. Consequently, while UFMC is heating, the matrix is expanding in axial direction. On the other hand, fiber is contracting in axial direction. Additionally, while UFMC is cooling, matrix is contracting. On the other hand, fiber is expanding in this state in axial direction. This reverse or mismatch behavior can cause inducing ILSs between fibers and matrix. If this process continues, it will create thermal cycles due to repeated cooling and heating. As a result of thermal cycling due to this 
TABLE 2: Axial shear modulus $\left(G_{\mathrm{F}}\right)$ and axial CTE $\left(\alpha_{\mathrm{F}}\right)$ of common fibers materials.

\begin{tabular}{lccc}
\hline No. & Fiber name & $\alpha_{\mathrm{F}}\left(10^{-6} /{ }^{\circ} \mathrm{C}\right)$ & $G_{\mathrm{F}}(\mathrm{GPa})$ \\
\hline 1 & T300 & $-0.54[19]$ & $8.97[19]$ \\
2 & C6000 & $-0.54[19]$ & $8.97[19]$ \\
3 & HMS & $-0.99[19]$ & $7.59[19]$ \\
4 & P75 & $-1.35[19]$ & $6.90[19]$ \\
5 & P100 & $-1.40[19]$ & $6.90[19]$ \\
6 & Diamond & $1.05[22]$ & $375[22]$ \\
7 & Sic & $2.78[20]$ & $190.7[20]$ \\
\hline
\end{tabular}

reverse behavior between fibers and matrix, bonds between them will start to break gradually and will create crack initiation along the axial direction of fibers within the fibers/ matrix interfaces. These cracks will grow as thermal cycle numbers increase and, ultimately, will cause fracture or failure within the UFMC. In Table 3, unidirectional diamond fibers/CE339 epoxy matrix has the highest ILSs max $_{\text {. It means }}$ that the probability of fracture due to thermal stress in this composite is the maximum. This fact is due to the high value of the axial CTE of CE339 epoxy matrix, and low axial CTE of diamond fibers. Additionally, the shear modulus of diamond is very high. Thus, ILSs $s_{\max }$, is highest for this UFMC material. Therefore, application of this UFMC material in low and high temperature environments with respect to crack-free temperature is not recommended. On the other hand, application of Sic fibers/borosilicate glass matrix composite is recommended because it has a minimum ILSs $_{\max }$ compared to other UFMCs. Moreover, as it is indicated in Table 3, ILSs $s_{\max }$ for most of the unidirectional Sic and diamond fibers composites is very high. It means that the application of diamond and Sic fibers, in most cases, is not recommended in thermal stress condition. The reason is the high shear modulus of these fibers and the mismatch of CTEs between these fibers and the matrix.

\section{Fatigue Behavior of Aluminum Foam}

Previously, compression-compression and tension-tension fatigue experiments for Alulight Aluminum foam have been evaluated. Stress-fatigue cycles curve has been derived for closed cell foam samples with compositions Al-1Mg-10Si and Al-1Mg-0.6Si (wt.\%). The results have shown that the fatigue life is very sensitive to the value of the stress which is applied to the sample [23].

Additionally, for the evaluation of the fatigue behavior of the aluminum foam, "Uniaxial Stress-Strain Behavior of Aluminum Alloy Foam" is submitted by McCullough et al. [24], "Compression Fatigue of a Cellular Al Alloy" is presented by Sugimura et al. [25], "On the Mechanical Performance of Closed Cell Al Alloy Foams" is provided by Sugimura et al. [26], "Fatigue Failure of an Open Cell and Closed Cell Aluminum Alloy Foam" is investigated by Harte et al. [27], and "Fatigue of Aluminum Alloy Foam" is submitted by Olurin et al. [28].

Another compression fatigue experiment has been done on aluminum-silicon foams under uniaxial cyclic stresses ranging from 50 to $80 \%$ of the total compression strength of
TABLE 3: Ranking of UFMCs based on ILSs $\mathrm{s}_{\max }$ calculated using values in Tables 1 and 2 .

\begin{tabular}{|c|c|c|}
\hline No. & UFMC name & $\mathrm{ILSs}_{\max }\left(10^{3} \mathrm{~Pa}\right)$ \\
\hline 1 & Sic fibers/borosilicate glass matrix & $87.70 \Delta T$ \\
\hline 2 & T300 fibers/borosilicate glass matrix & $99.00 \Delta T$ \\
\hline 3 & C6000 fibers/borosilicate glass matrix & $99.00 \Delta T$ \\
\hline 4 & HMS fibers/borosilicate glass matrix & $110.8 \Delta T$ \\
\hline 5 & P75 fibers/borosilicate glass matrix & $120.3 \Delta T$ \\
\hline 6 & P100 fibers/borosilicate glass matrix & $121.6 \Delta T$ \\
\hline 7 & P75 fibers/PMR15 polyimide matrix & $257.7 \Delta T$ \\
\hline 8 & P100 fibers/PMR15 polyimide matrix & $258.0 \Delta T$ \\
\hline 9 & HMS fibers/PMR15 polyimide matrix & $280.8 \Delta T$ \\
\hline 10 & P75 fibers/epoxy 934 matrix & $312.4 \Delta T$ \\
\hline 11 & P100 fibers/epoxy 934 matrix & $312.7 \Delta T$ \\
\hline 12 & T300 fibers/PMR15 polyimide matrix & $327.8 \Delta T$ \\
\hline 13 & C6000 fibers/PMR15 polyimide matrix & $327.8 \Delta T$ \\
\hline 14 & HMS fibers/epoxy 934 matrix & $340.9 \Delta T$ \\
\hline 15 & T300 fibers/epoxy 934 matrix & $398.8 \Delta T$ \\
\hline 16 & C6000 fibers/epoxy 934 matrix & $398.8 \Delta T$ \\
\hline 17 & P75 fibers/CE339 epoxy matrix & $446.5 \Delta T$ \\
\hline 18 & P100 fibers/CE339 epoxy matrix & $446.8 \Delta T$ \\
\hline 19 & T300 fibers/AZ91D Mg matrix & $482.0 \Delta T$ \\
\hline 20 & HMS fibers/CE339 epoxy matrix & $488.4 \Delta T$ \\
\hline 21 & HMS fibers/AZ91D Mg matrix & $489.5 \Delta T$ \\
\hline 22 & P75 fibers/AZ91D Mg matrix & $495.5 \Delta T$ \\
\hline 23 & P100 fibers/AZ91D Mg matrix & $496.3 \Delta T$ \\
\hline 24 & T300 fibers/CE339 epoxy matrix & $573.2 \Delta T$ \\
\hline 25 & C6000 fibers/CE339 epoxy matrix & $573.2 \Delta T$ \\
\hline 26 & T300 fibers/A199.5 matrix & $601.6 \Delta T$ \\
\hline 27 & C6000 fibers/Al99.5 matrix & $601.6 \Delta T$ \\
\hline 28 & HMS fibers/Al99.5 matrix & $613.34 \Delta T$ \\
\hline 29 & P75 fibers/Al99.5 matrix & $622.7 \Delta T$ \\
\hline 30 & P100 fibers/A199.5 matrix & $624.0 \Delta T$ \\
\hline 31 & T300 fibers/6061 aluminum matrix & $627.6 \Delta T$ \\
\hline 32 & C6000 fibers/6061 aluminum matrix & $627.6 \Delta T$ \\
\hline 33 & HMS fibers/6061 aluminum matrix & $639.34 \Delta T$ \\
\hline 34 & P75 fibers/6061 aluminum matrix & $648.7 \Delta T$ \\
\hline 35 & P100 fibers/6061 aluminum matrix & $650.0 \Delta T$ \\
\hline 36 & T300 fibers/2024 aluminum matrix & $655.3 \Delta T$ \\
\hline 37 & C6000 fibers/2024 aluminum matrix & $655.3 \Delta T$ \\
\hline 38 & HMS fibers/2024 aluminum matrix & $667.7 \Delta T$ \\
\hline 39 & P75 fibers/2024 aluminum matrix & $677.6 \Delta T$ \\
\hline 40 & P100 fibers/2024 aluminum matrix & $679.0 \Delta T$ \\
\hline 41 & Diamond fibers/borosilicate glass matrix & $821.2 \Delta T$ \\
\hline 42 & Sic fibers/A199.5 matrix & $3,779.7 \Delta T$ \\
\hline 43 & Sic fibers/2024 aluminum matrix & $3,897.9 \Delta T$ \\
\hline 44 & Sic fibers/6061 aluminum matrix & $3,970 \Delta T$ \\
\hline 45 & Sic fibers/AZ91D Mg matrix & $4,904.8 \Delta T$ \\
\hline 46 & Sic fibers/PMR15 polyimide matrix & $6,335 \Delta T$ \\
\hline 47 & Diamond fibers/Al99.5 matrix & $8,081.2 \Delta T$ \\
\hline 48 & Diamond fibers/2024 aluminum matrix & $8,313.75 \Delta T$ \\
\hline 49 & Diamond fibers/6061 aluminum matrix & $8,456.2 \Delta T$ \\
\hline 50 & Diamond fibers/AZ91D Mg matrix & $10,293.7 \Delta T$ \\
\hline 51 & Sic fibers/CE339 epoxy matrix & $11,552.6 \Delta T$ \\
\hline 52 & Diamond fibers/PMR15 polyimide matrix & $13,106.2 \Delta T$ \\
\hline 53 & Diamond fibers/epoxy 934 matrix & $16,076.2 \Delta T$ \\
\hline 54 & Diamond fibers/CE339 epoxy matrix & $23,366.2 \Delta T$ \\
\hline
\end{tabular}

the samples. For producing these samples, aluminum powder was combined with 7 wt.\% silicon powders. Furthermore, $0.5 \%$ titanium hydride has been added to the sample. The samples had a cylindrical shape with height 
equal to $60 \mathrm{~mm}$ and diameter equal to $44 \mathrm{~mm}$. The produced foams had densities $0.55,0.63$, and $0.94 \mathrm{~g} / \mathrm{cm}^{3}$ [29].

Furthermore, another fatigue experiment with compression-compression loading was performed on closed-cell aluminum foam in 2008. Observations have shown that noticeable hardening under loading may occur which is accompanied with plastic deformation within quasi-static loading [30].

It seems that the main reason for applying $\mathrm{Al}$ foam in different industries is due to its lightweight. Aluminum foam Sandwich is one of the panels that could be used in structural applications. Hence, shear fatigue behavior of this material has been investigated. The experiment has shown that mechanical behavior of this Al foam Sandwich seems to be highly dependent on cells distribution, morphology, and manufacturing process [31].

Metal foams are produced and developed due to their unique properties such as chemical reactions, damping capacity, energy absorption, and low stiffness to density ratio. Fatigue can occur in foams even at low applied stress due to the existence of maximum stress located on the foam microstructure nodes. Fatigue can affect the material parameters and macroscopic behavior of the specimen due to the influence imposed by the different number of stress cycles and stress amplitude [32].

In 2013, another compression-compression fatigue experiment has been performed. The objective of the cyclic loading experiment was to determine the load amount for failure cycles of $10^{5}$. The results have revealed that application of 50\% of compression strength for the cyclic load is very low for obtaining $10^{5}$ cycles for the fatigue life [33].

Metal matrix foams can be applied as load bearing, energy absorber, and vibration damping in structural parts and machine beds. Metal matrix foams show good stability under compression cyclic loads. Deformation of these foams under compression cyclic loads occurs in three stages. First stage is the linear increase of strain with increasing fatigue cycles. Second stage is the accumulation of strain in many numbers of cycles. Third stage is the rapid strain accumulation during few cycles until failure occurs. The experiment also has indicated that fatigue limit in case of tension is twice less than in the case of compression loading [34].

\section{Interlaminar Shear Stress Comparison between SWCNT/Aluminum Foam and MWCNT/Aluminum Foam}

In the presented part of the study, ILSs within the interfaces between the fibers and matrix, by using experimental data and applying analytical method, between SWCNT/aluminum foam and MWCNT/aluminum foam are compared. In order to compare the ILSs of these two nanocomposites, the following procedure has been followed. The mismatch of coefficients of thermal expansion between fibers and matrix in both nanocomposites is compared. According to the results obtained, it appears that MWCNT/aluminum foam can offer lower ILSs when compared to SWCNT/aluminum foam. The reason is, based on the evidence achieved by the mentioned analytical method, SWCNT/aluminum foam, in average, offers higher mismatch between coefficients of thermal expansion and interlaminar shear stress within the fibers and matrix interfaces. Thus, further stress concentration in these areas may result in higher crack propagation rate that can cause fracture.

The application of aluminum foam is nowadays very broad in many industries such as transport vehicles. The reason behind is the mechanical properties of aluminum foam such as fire resistance, acoustic insulator, shock absorption, low thermal conductivity, suppress vibrations, and mitigation explosion effects. Furthermore, aluminum foam is now a popular material for advanced material for structural purpose due to its lightweight, crashworthy, thermally insulate, and cheap price. Additionally, aluminum foam offers novel physical, mechanical, and electrical properties along with low density, which makes it a suitable material for aeronautical industry. Moreover, this material can be used as a cellular material that may be applied to different applications such as cores for Sandwich panels, energy absorption elements for automotive industries, and many multifunctional structural elements in vehicles [35].

Increasing ILSs within the fibers and matrix interfaces can result in stress concentration in these areas. The stress concentration may cause crack initiation, propagation, and de-bonding between the fibers and matrix.

It appears that there is no research related to comparison of ILSs between SWCNT/aluminum foam (SWCNTAF) and MWCNT/aluminum foam (MWCNTAF). Therefore, in the presented part of the study, by using the assumptions in Section 2, and applying experimental data [32,33], ILSs between SWCNTAF and MWCNTAF are compared. The results of this research may contribute to selecting the best nanocomposite between these two, to apply in thermal cycling environment.

\subsection{Experimental Procedures}

4.1.1. CNT Experimental Procedures. "Spinnable MWCNT arrays were obtained by chemical vapor deposition using $\mathrm{C}_{2} \mathrm{H}_{2}$ and $\mathrm{FeCl}_{2}$ as the base material and the catalyst, respectively. The diameter of the MWCNTs was measured using a transmission electron microscope (TEM, JEOL JEM$2100 \mathrm{~F}$, Japan). A partially cured epoxy resin (B-stage epoxy) with a release paper was used as the starting material, where the epoxy resin comprised bisphenol-A type epoxy, novolactype epoxy, and an aromatic diamine curing agent. The epoxy resin was then impregnated into the MWCNT monolithic sheet at $90^{\circ} \mathrm{C}$ for $3 \mathrm{~min}$ between the steel plates of a hot press (AS ONE AH-4015, Japan). After peeling off the release paper from the MWCNT sheet now impregnated with the epoxy resin (prepreg sheet), the prepreg sheet was cured at $130^{\circ} \mathrm{C}$ for $1.5 \mathrm{~h}$ at a pressure of $1 \mathrm{MPa}$ using the hot press, forming a film specimen" [36].

4.1.2. Al Foam Experimental Procedures. "Another way of foaming the melts is to directly add a foaming agent to the molten metal. The foaming agent releases gas by 
decomposition under the influence of heat which then carries out the foaming process. Shinko Wire Company, Japan has been manufacturing foamed aluminum under the registered name "Alporas." This process initially involves addition of $1.5 \%$ of calcium to the molten aluminum for adjusting the viscosity and secondly addition of molten aluminum at $670^{\circ} \mathrm{C}$ to $690^{\circ} \mathrm{C}$, stirred for 6 to 10 minutes in an ambient atmosphere. It thickens the aluminum melt which is then poured into a casting mould and stirred with addition of powdered $\mathrm{TiH} 2$ (foaming agent) by using a rotating impeller. Addition of a sufficient amount of hydride (usually 1.6\%) decomposes the melt under the influence of heat and it releases hydrogen gas. As a result, the foam expands and fills up the mould within 15 to 20 minutes. It is cooled by air (at room temperature) in the mould and solidifies as a block with porosity between $85 \%$ and $95 \%$. The production rate of Alporas is reported to be $1000 \mathrm{~kg} /$ day by application of the batch casting process. This process is capable of producing large blocks of good quality foams. This process is capable of producing large blocks of good quality foams such as Blocks of $450 \mathrm{~mm}$, the Alporas process, and GASCAR process. The required width, $2050 \mathrm{~mm}$ length, and $650 \mathrm{~mm}$ height can be produced with this technique. These foams have uniform pore structure and they are better than the foams which are produced with addition of ceramic particles. The latter process makes foams brittle. However, addition of hydride, which requires complex processing equipment, makes the process more expensive than the one in which foaming of melts is carried out by gas injection. The density range of these foams is $0.18-0.24 \mathrm{gcm}^{-3}$ and the mean pore size is about $4.5 \mathrm{~mm}$. Addition of calcium powder in aluminum melt enhances the viscosity of the melt. With increased viscosity, flow of aluminum melt slows down, resulting in its reduced drainage before solidification" [37].

4.2. Problem Formulation. In Table 4, shear modulus and CTEs of SWCNT, MWCNT, and aluminum foam (AF) at temperature range of -5 to $85^{\circ} \mathrm{C}$ are indicated. For performing the thermal analysis to compare the ILSs between MWCNTAF and SWCNTAF, the data in Table 4 and equation (1) [18] are used.

As it has been mentioned in Section 2 of the manuscript, equation (1) can contribute to estimate the probability of crack initiation and/or propagation within the SWCNTAF and MWCNTAF. With this assumption, by employing the data in Table 4 and using equation (1), ILSs in both SWCNTAF and MWCNTAF can be approximated.

4.3. Results and Discussion. As it is indicated in Figures 2-5, most of the results are the evidence of lower ILSs within the MWCNTAF in comparison to that within the SWCNTAF. The reason is that the average mismatch of CTEs between SWCNT and AF is $0.88 \%$ more than that between the MWCNT and AF. Hence, maximum ILSs within the SWCNTAF is $399 \%$ more than that within the MWCNTAF. Additionally, average ILSs within the SWCNTAF is 349\% more than that within the MWCNTAF. The only result that makes the opposite conclusion is the difference of CTEs between SWCNT and AF that is 19\% less than that between MWCNT and AF. It means that, based on the results obtained in this study, it appears that crack initiation and/or propagation on interfaces between the nanofiber and matrix within the SWCNTAF may occur with higher probability when compared to that within the MWCNTAF. This result suggests using MWCNTAF instead of SWCNTAF in cases dealing with thermal cycling condition for having a longer thermal life.

\section{Enhancing Thermal Fatigue Resistance Using Unidirectional SWCNT/Aluminum Foam Composite Material}

The significant purpose of this section of this research is to use a method to compare the thermal fatigue resistance of unidirectional SWCNT/aluminum foam with unidirectional SWCNT/epoxy. The reason is that the application of SWCNT/epoxy is nowadays very common in many industries such as aerospace and automobile due its lightweight and high strength. In this part of the study, by using analytical method, the interlaminar shear stresses on interfaces of fibers/matrix in both nanocomposites are derived and compared. With the analysis of these results, it is determined that the risk of crack initiation and/or propagation due to stress concentration on interfaces of fibers/matrix is higher within the SWCNT/epoxy in comparison to that within the SWCNT/aluminum foam. Thus, thermal fatigue resistance of these two nanocomposites could be compared with this analysis. The results have shown that the thermal fatigue life could be enhanced by application of unidirectional SWCNT/aluminum foam because interlaminar shear stress within the SWCNT/aluminum foam is less than that within the SWCNT/epoxy. These results are very advantageous because replacing epoxy with aluminum foam could decrease the manufacturing costs due to lower price of aluminum foam.

In order to have the best design, it seems enough to try to have a best match for CTEs between the nanocomposites components such as fibers and matrix. It means that, according to this theory, fibers and epoxy should have similar values of CTEs to offer less interlaminar shear stress (ILSs) and higher thermal fatigue life.

Many studies have been performed to estimate the thermal fatigue life of nanocomposites and composites such as UD CF/EP. Nevertheless, it seems that there is no study to evaluate the thermal fatigue life of unidirectional SWCNT/ aluminum foam (USWCNTAF).

In the presented part of the study, by applying analytical method, it is tried to compare the thermal fatigue life of USWCNTAF with unidirectional SWCNT/epoxy (USWCNTE). The results have shown that USWCNTAF could offer higher thermal fatigue resistance when compared with USWCNTE.

5.1. Problem Formulation. According to the results of the research in 2018 [18], it seems that, with increasing ILSs, thermal fatigue life decreases. In Table 5, CTEs and shear 
TABLE 4: CTEs and shear modulus of SWCNT, MWCNT, and AF at temperature range of -5 to $85^{\circ} \mathrm{C}$.

\begin{tabular}{|c|c|c|c|c|c|c|}
\hline \multirow{2}{*}{$\begin{array}{l}\text { Temperature } \\
\left({ }^{\circ} \mathrm{C}\right)\end{array}$} & \multicolumn{2}{|c|}{ SWCNT } & \multicolumn{2}{|c|}{ MWCNT } & \multicolumn{2}{|c|}{$\mathrm{AF}$} \\
\hline & $\begin{array}{c}\mathrm{CTE}\left(1 /{ }^{\circ} \mathrm{C} e-5\right) \\
{[36]}\end{array}$ & $\begin{array}{l}\text { Shear modulus } \\
\quad(\mathrm{GPa})[37]\end{array}$ & $\begin{array}{c}\mathrm{CTE}\left(1 /{ }^{\circ} \mathrm{C} e-5\right) \\
{[36]}\end{array}$ & $\begin{array}{l}\text { Shear modulus } \\
\text { (GPa) [37] }\end{array}$ & $\begin{array}{c}\mathrm{CTE}\left(1 /{ }^{\circ} \mathrm{C} e-5\right) \\
{[35]}\end{array}$ & $\begin{array}{l}\text { Shear modulus } \\
\text { (GPa) [35] }\end{array}$ \\
\hline-5 & -1.04 & 18 & -2.0 & 4 & 2.3 & 5.2 \\
\hline 0 & -1.05 & 18 & -1.8 & 4 & 2.3 & 5.2 \\
\hline 5 & -1.06 & 18 & -1.6 & 4 & 2.3 & 5.2 \\
\hline 10 & -1.07 & 18 & -1.4 & 4 & 2.3 & 5.2 \\
\hline 15 & -1.08 & 18 & -1.3 & 4 & 2.3 & 5.2 \\
\hline 20 & -1.10 & 18 & -1.1 & 4 & 2.3 & 5.2 \\
\hline 25 & -1.11 & 18 & -1.0 & 4 & 2.3 & 5.2 \\
\hline 30 & -1.12 & 18 & -0.9 & 4 & 2.3 & 5.2 \\
\hline 35 & -1.12 & 18 & -0.8 & 4 & 2.3 & 5.2 \\
\hline 40 & -1.13 & 18 & -0.8 & 4 & 2.3 & 5.2 \\
\hline 45 & -1.14 & 18 & -0.8 & 4 & 2.3 & 5.2 \\
\hline 50 & -1.15 & 18 & -0.7 & 4 & 2.3 & 5.2 \\
\hline 55 & -1.16 & 18 & -0.8 & 4 & 2.3 & 5.2 \\
\hline 60 & -1.16 & 18 & -0.8 & 4 & 2.3 & 5.2 \\
\hline 65 & -1.17 & 18 & -0.8 & 4 & 2.3 & 5.2 \\
\hline 70 & -1.18 & 18 & -0.9 & 4 & 2.3 & 5.2 \\
\hline 75 & -1.18 & 18 & - & 4 & 2.3 & 5.2 \\
\hline 80 & -1.19 & 18 & - & 4 & 2.3 & 5.2 \\
\hline 85 & -1.19 & 18 & - & 4 & 2.3 & 5.2 \\
\hline
\end{tabular}

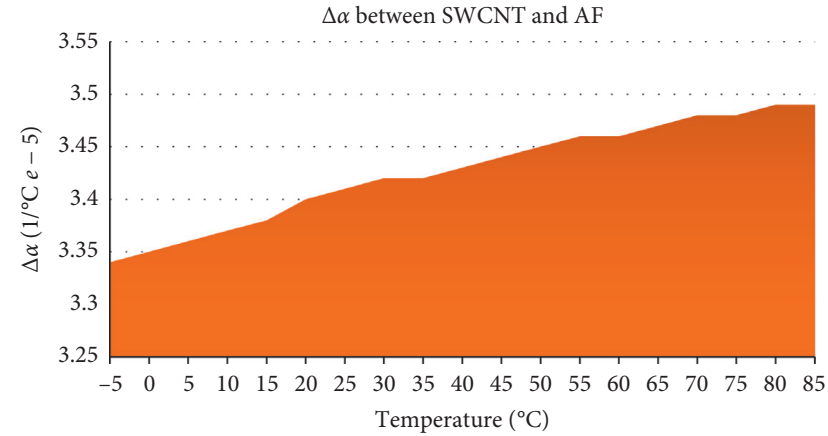

FIgUre 2: Mismatch between the CTEs of SWCNT and AF $(\Delta \alpha)$ in temperature range of -5 to $85^{\circ} \mathrm{C}$ within the SWCNTAF.

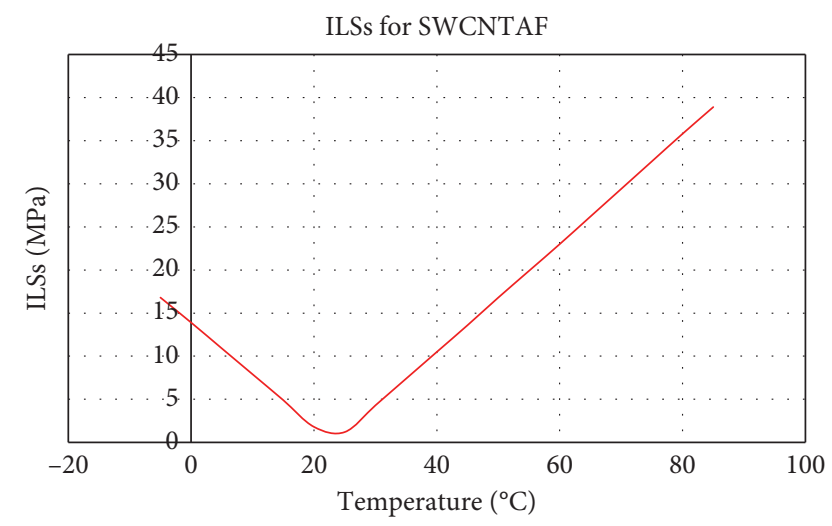

FIGURE 3: ILSs over the interfaces between SWCNT and AF at temperature range of -5 to $85^{\circ} \mathrm{C}$ within the SWCNTAF.

modulus of SWCNT, epoxy, and aluminum foam at temperature range -5 to $85^{\circ} \mathrm{C}$ are indicated. With the presented data in Table 5 and using equation (1), in the Results and

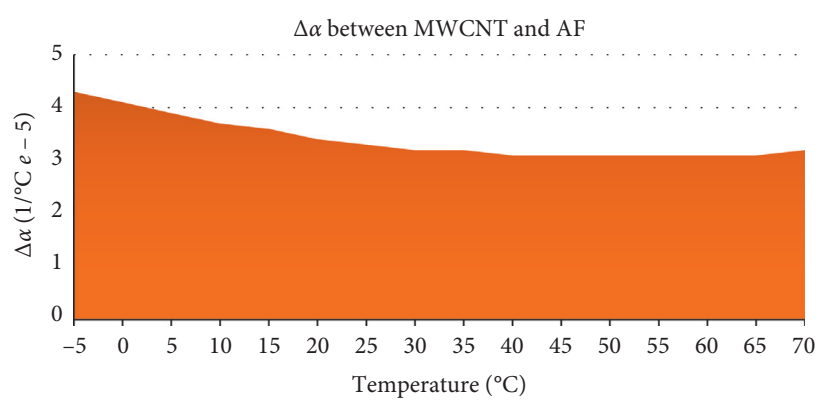

FIGURE 4: Mismatch between the CTEs of MWCNT and AF $(\Delta \alpha)$ in temperature range of -5 to $70^{\circ} \mathrm{C}$ within the MWCNTAF.

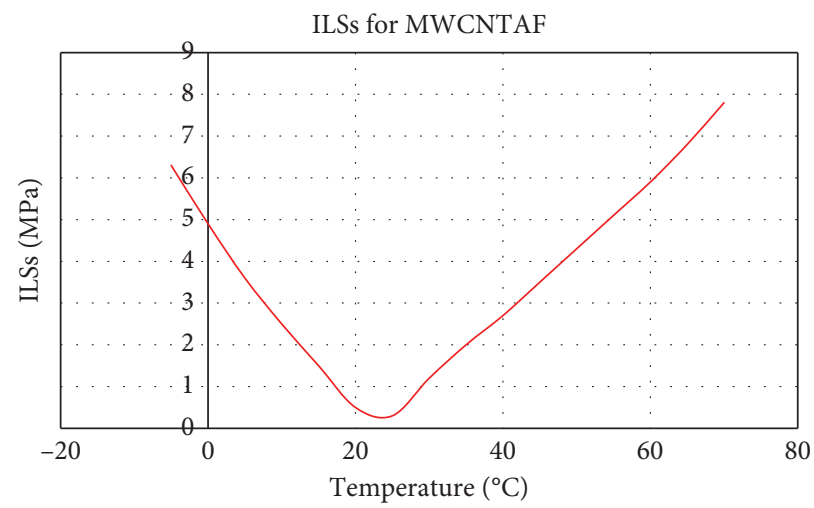

FIGURE 5: ILSs within the interfaces between MWCNT and AF at temperature range of -5 to $70^{\circ} \mathrm{C}$ within the MWCNTAF.

Discussion section of this part of the manuscript, thermal fatigue resistance of USWCNTAF and that of USWCNTE are compared. 
TABLE 5: CTEs and shear modulus of SWCNT, epoxy, and aluminum foam at temperature range of -5 to $80^{\circ} \mathrm{C}$.

\begin{tabular}{|c|c|c|c|c|c|c|}
\hline \multirow{2}{*}{$\begin{array}{l}\text { Temperature } \\
\left({ }^{\circ} \mathrm{C}\right)\end{array}$} & \multicolumn{2}{|c|}{ SWCNT } & \multicolumn{2}{|c|}{ Epoxy } & \multicolumn{2}{|c|}{ Aluminum foam } \\
\hline & $\begin{array}{c}\mathrm{CTE}\left(1 /{ }^{\circ} \mathrm{C} e-5\right) \\
{[36]}\end{array}$ & $\begin{array}{l}\text { Shear modulus } \\
\text { (GPa) [37] }\end{array}$ & $\begin{array}{c}\mathrm{CTE}\left(1 /{ }^{\circ} \mathrm{C} e-5\right) \\
{[36]}\end{array}$ & $\begin{array}{l}\text { Shear modulus } \\
\text { (GPa) [19] }\end{array}$ & $\begin{array}{c}\mathrm{CTE}\left(1 /{ }^{\circ} \mathrm{C} e-5\right) \\
{[35]}\end{array}$ & $\begin{array}{c}\text { Shear modulus } \\
\text { (GPa) [35] }\end{array}$ \\
\hline-5 & -1.04 & 18 & 4.60 & 1.59 & 2.3 & 5.2 \\
\hline 0 & -1.05 & 18 & 4.95 & 1.59 & 2.3 & 5.2 \\
\hline 5 & -1.06 & 18 & 5.30 & 1.59 & 2.3 & 5.2 \\
\hline 10 & -1.07 & 18 & 4.60 & 1.59 & 2.3 & 5.2 \\
\hline 15 & -1.08 & 18 & 4.00 & 1.59 & 2.3 & 5.2 \\
\hline 20 & -1.10 & 18 & 3.70 & 1.59 & 2.3 & 5.2 \\
\hline 25 & -1.11 & 18 & 3.50 & 1.59 & 2.3 & 5.2 \\
\hline 30 & -1.12 & 18 & 3.53 & 1.59 & 2.3 & 5.2 \\
\hline 35 & -1.12 & 18 & 3.80 & 1.59 & 2.3 & 5.2 \\
\hline 40 & -1.13 & 18 & 4.15 & 1.59 & 2.3 & 5.2 \\
\hline 45 & -1.14 & 18 & 4.30 & 1.59 & 2.3 & 5.2 \\
\hline 50 & -1.15 & 18 & 4.50 & 1.59 & 2.3 & 5.2 \\
\hline 55 & -1.16 & 18 & 4.70 & 1.59 & 2.3 & 5.2 \\
\hline 60 & -1.16 & 18 & 4.90 & 1.59 & 2.3 & 5.2 \\
\hline 65 & -1.17 & 18 & 5.00 & 1.59 & 2.3 & 5.2 \\
\hline 70 & -1.18 & 18 & 5.20 & 1.59 & 2.3 & 5.2 \\
\hline 75 & -1.18 & 18 & 5.40 & 1.59 & 2.3 & 5.2 \\
\hline 80 & -1.19 & 18 & 5.60 & 1.59 & 2.3 & 5.2 \\
\hline 85 & -1.19 & 18 & 5.70 & 1.59 & 2.3 & 5.2 \\
\hline
\end{tabular}

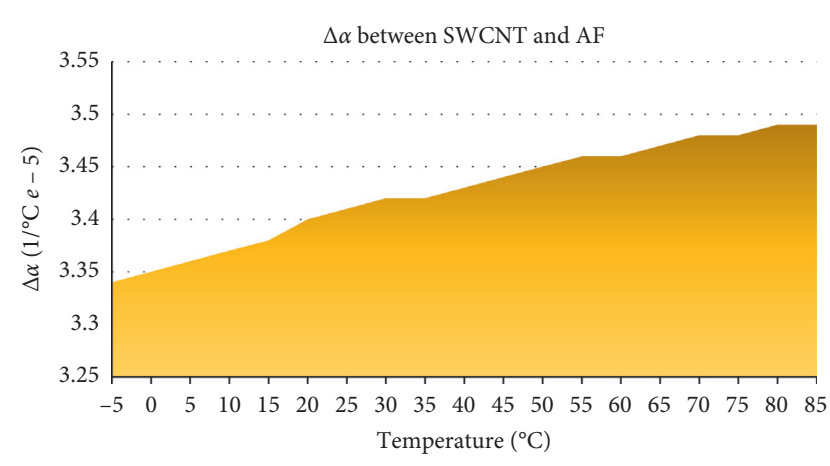

Figure 6: Mismatch between the CTEs of SWCNT and AF $(\Delta \alpha)$ in temperature range of -5 to $85^{\circ} \mathrm{C}$ within SWCNTAF.

5.2. Results and Discussion. By analyzing the results which are shown in Figures 6-9, it can be observed that at temperature range of -5 to $85^{\circ} \mathrm{C}$ the maximum mismatches of CTEs and ILSs are $49 \%$ decreased in SWCNTAF in comparison with that within the SWCNTE. Additionally, mean mismatch of CTEs within the SWCNTAF is $40 \%$ decreased in comparison with that within the SWCNTE. Moreover, average ILSs in SWCNTAF is $44 \%$ decreased in comparison with that in SWCNTE.

Finally, by summing up all the results, it can be concluded that, due to the decrease of CTEs mismatches and ILSs in SWCNTAF in comparison with that in SWCNTE, thermal fatigue life in SWCNTAF seems to be higher than that in SWCNTE. The reason is that, by decreasing the CTEs mismatches and ILSs, the stress concentration on interfaces between SWCNT and AF decreases. By decreasing the stress concentration on interfaces between SWCNT and AF, the probability of crack initiation and/or propagation decreases. Thus, the chance of de-bonding between SWCNTs and AF

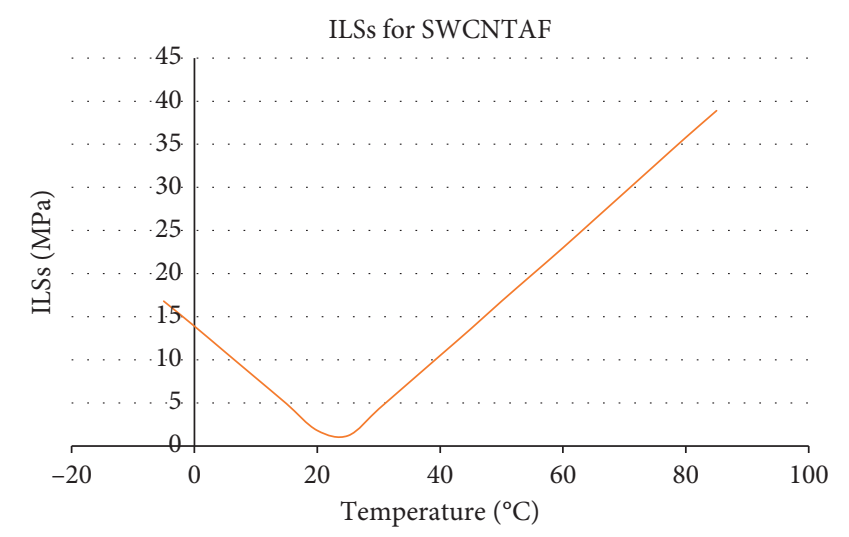

FIgURE 7: ILSs on interfaces of SWCNT and AF at temperature range of -5 to $85^{\circ} \mathrm{C}$ in SWCNTAF.

decreases. This will result in postponing the fatigue failure or fracture. Hence, the thermal fatigue life of SWCNTAF could be higher than SWCNTE.

\section{Interaction between Carbon and Molten Aluminum}

In 1990, Metal-Matrix Composites (MMCs) were introduced to use in structural applications. They were also recommended to use for thermal management applications. Their characteristics were 1 . high temperature operating, 2. improved strength, 3. higher stiffness, 4. higher thermal conductivity, 5. abrasion resistance, 6 . creep resistance, and 7. dimensional stability [38].

6.1. Aluminum-Matrix Composites. Aluminum-Matrix Composites were used due to their lightweight, environmental resistance, and enough melting point for many 
applications. Furthermore, aluminum could accommodate with different fibers, including $\mathrm{AL}_{2} \mathrm{O}_{3}$, Sic, boron, graphite fibers, and many other particles [38].

In 2000, Pippel et al. performed a research to characterize the interlayer structure of carbon fiber reinforced aluminum wires. According to the results of their research, the structure of the interlayer between fiber and matrix has a thickness of 2-4 nm and consists of carbon enriched with aluminum. Within the layer, 1-2 nm grains are sometimes observed. These grains have a lattice plane distance around $0.26 \mathrm{~nm}$. Furthermore, the interlayers contain needles or platelets which are aluminum carbide. Based on the experiments, "the growth of the carbide needles or platelets starts immediately from the thin amorphous aluminumcontaining surface layer of the fiber" [39].

In the condition that carbon and aluminum are in contact with each other for several minutes, chemical reaction could occur between them and contact angle between them will decrease. This results in producing aluminum carbide $\left(\mathrm{Al}_{4} \mathrm{C}_{3}\right)$. This production is called wetting. This can happen at temperatures above $550^{\circ} \mathrm{C}$, but in temperatures above $900^{\circ} \mathrm{C}$ reaction can happen at a faster rate and it decomposes to $\mathrm{Al}_{2} \mathrm{O}$ vapor [40].

Aluminum (Al) carbide is a hygroscopic ceramic which is brittle and has a high hardness. Thus, it can act as a stress concentrator. As a result, it fails at relatively low strain. Aluminum carbide also is vulnerable to galvanic corrosion. In axial direction along the fibers, the CTE of carbon fiber (CF) is negative, while the CTE of $\mathrm{Al}$ is the same positive value in all directions. As a result, in manufacturing process of $\mathrm{CF} / \mathrm{Al}$ composites when the temperature drops below $340^{\circ} \mathrm{C}$ thermal stresses will appear. In order to prevent forming $\mathrm{Al}$ carbide, fiber coating, less reactive fibers, and limiting time in manufacturing process are recommended [40].

The results have shown that melting point of CNT is around $3500^{\circ} \mathrm{C}$ and MWCNTs are in a stable condition even in temperatures higher than $2800^{\circ} \mathrm{C}$. Nevertheless, two failure mechanisms are most likely to occur. 1. If MWCNT is stronger than matrix and interface, the nanocomposite will fail pulling out of MWCNTs 2. If matrix and interface are stronger than MWCNT, the failure occurs through the stochastic breakage of MWCNT at the weakest sites along its length [41].

In solidification of MMC, reinforcement is combined with the liquid metal. The solidification process can be divided into two parts: 1 . stir mixing; 2 . melt infiltration [42].

"Defects in activated carbon and in CNTs provide sites for chemical reactions to occur. Reactions of CNT with metal matrix leading to carbide formation have been observed by many researchers. The small size and amount of $\mathrm{Al}_{4} \mathrm{C}_{3}$ formed was due to the smaller availability of defective sites and amorphous carbon. The formation of carbide also depends on the processing techniques. Some researchers have reported no formation of $\mathrm{Al}_{4} \mathrm{C}_{3}$ in the case of solid-state processes such as extrusion. On the other hand, there would be no existence of CNT in the matrix when heated up to $1073 \mathrm{~K}$ and XRD results show that CNT fully converts to $\mathrm{Al}_{4} \mathrm{C}_{3}$. The reaction at the triple point between liquid alloy and CNT leads to formation of carbide and subsequent spreading of metal. Minimal reaction of CNT is desirable in order that efficient stress transfer can occur without much damage to the CNT structure" [43].

"The application of a sputter-coated layer of aluminum on the CNTs resulted in the encapsulation of all exposed nanotubes for light deposition and the formation of a $1 \mu \mathrm{m}$-thick composite layer for longer deposition, a promising result which strongly suggests an affinity between the two materials. This observation highlights the potential for non-destructively impregnating the CNT forests with aluminum, a technique demonstrated previously with a polymer matrix" [44].

"The results show a good distribution of the matrix between the CFs when using higher casting pressures of 38 and $53 \mathrm{MPa}$, lower pouring temperature of $\left(700^{\circ} \mathrm{C}\right)$, and lower die temperatures of 100 and $200^{\circ} \mathrm{C}$. This will result in higher ultimate tensile strength of $\mathrm{CF} / \mathrm{Al}-\mathrm{Si}$ because of the increased bonding, decreased shrinkage defects, and fibers degradation" [45].

Due to the high specific strength, high modulus, and low $\mathrm{CTE}$ in $\mathrm{CF} / \mathrm{Al}$ composites, they have been used in electronic and space industries. However, the reaction between $\mathrm{CF}$ and $\mathrm{Al}$ may take place in $\mathrm{CF} / \mathrm{Al}$ composites [45]:

$$
4 \mathrm{Al}+3 \mathrm{C} \longrightarrow \mathrm{Al}_{4} \mathrm{C}_{3}
$$

Interaction between $\mathrm{Al}$ and $\mathrm{CF}$ can produce $\mathrm{Al}_{4} \mathrm{C}_{3}$ which is an interface drawback that is related to MMCs manufactured by liquid state procedure. Formation of $\mathrm{Al}_{4} \mathrm{C}_{3}$ on the interfaces degrades the mechanical properties of the $\mathrm{CF} /$ Al composite [45].

$\mathrm{CF} / \mathrm{Al}$ composites are not easily recyclable due to the reaction of carbon with molten aluminum or the reaction of carbide with molten aluminum. The results have shown changes of enthalpy at temperatures over $650^{\circ} \mathrm{C}$ due to the phase change as aluminum enters the molten state. Furthermore, the experiments have shown that, at temperature $850^{\circ} \mathrm{C}$, molten aluminum interacts effectively with Sic on their interfaces. This will cause dissolving silicon that will produce aluminum and aluminum carbide [46].

The results of experiments have shown that, at $1.5 \mathrm{wt} . \%$ MWCNTs, elongation percentage and ultimate tensile strength are maximum values in MWCNTs/A356 aluminum alloy. MWCNT/A356 aluminum alloy can be applied in machinery, aircraft, and automobile industries due to its low-cost aluminum and mechanical properties. In automobile industry, this nanocomposite can be used to replace steel components and applications such as pistons, cylinder liners, and connecting rods [47].

While producing $\mathrm{CF} / \mathrm{Al}$ alloy composite, $\mathrm{Al}_{4} \mathrm{C}_{3}$ carbides may develop on the surface of CFs. Furthermore, at pressure infiltration process, CFs can burn and release gasses that could cause crack initiation due to thermal stress. Fiber clustering, poor wettability, chemical 


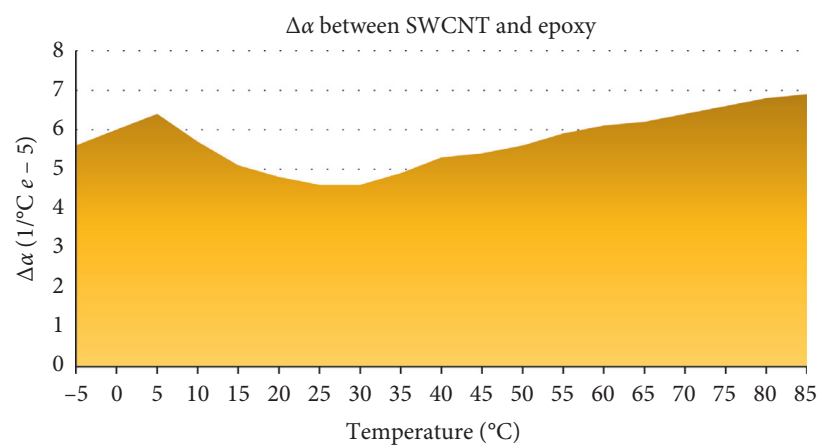

FIgure 8: Mismatch between the CTEs of SWCNT and epoxy $(\Delta \alpha)$ in temperature range of -5 to $85^{\circ} \mathrm{C}$ in SWCNTE.

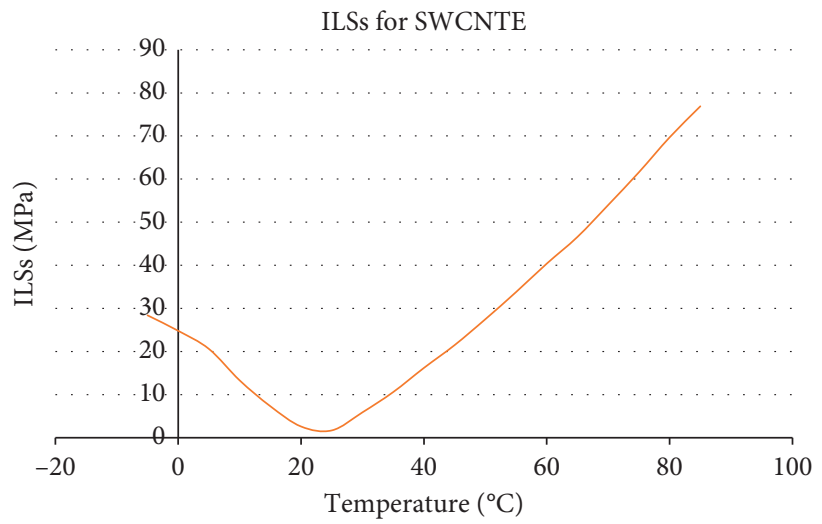

FIGURE 9: ILSs on interfaces of SWCNT and epoxy at temperature range of -5 to $85^{\circ} \mathrm{C}$ in SWCNTE.

reaction on fiber/liquid aluminum interfaces, porosities, and non-homogeneity in CFs distribution are the restrictions of applying $\mathrm{CF} / \mathrm{Al}$ alloy composites in many industries [48].

Low interfacial strength in matrix/fibers areas, intermetallic formation, poor infiltration, and low tensile strength are considered as main issues in $\mathrm{CF} / \mathrm{Al}$ composite fabrication. $\mathrm{Al}_{4} \mathrm{C}_{3}$ particles present at interfaces can cause cracking in CF coating under high pressure. This is due to the nucleation of carbide and heterogeneous growing from $\mathrm{CFs}$ into the $\mathrm{Al}$ due to interfacial reaction. The other challenge is the reaction of CF with molten $\mathrm{Al}$ that will cause air bubbles arrested in Al. These bubbles can act as crack formation sites under loading. In some circumstances, the formation of carbide $\left(\mathrm{Al}_{4} \mathrm{C}_{3}\right)$ on interfaces can cause flat fractures areas without fiber to pull out due to brittleness of the CF/Al composite [49].

Low wettability between CNTs and $\mathrm{Al}$, oxidation of molten metal, and consequent reduction in mechanical properties are the challenges to produce $\mathrm{CNT} / \mathrm{Al}$ composite. Argon as an inert gas can be applied in fusion process to prevent the oxidation in aluminum [50].

Experiments have shown that in $\mathrm{CNTs} / \mathrm{Al}$ composite self-ion irradiation can convert the CNTs to $\mathrm{Al}_{4} \mathrm{C}_{3}$ which is metastable. Uniform dispersion of CNTs in Al can build internal interfaces which are prolific in $\mathrm{Al}$ that may cause venues in radiation defects situations to self-heal (recombine). Irradiation experiments with $\mathrm{Al}$ ion and helium have shown that if CNTs can be dispersed uniformly in $\mathrm{Al}$, they can decrease the embrittlement and hardening due to radiation [51].

The best vol.\% of CNTs in CNTs/Al composite is $1 \%$ because the number of clusters and pores are less, and the hardness is maximum. Furthermore, at this amount of CNT, CNT clusters have smaller size. Moreover, higher value of CNT may cause CNTs non-uniformity in CNT/Al composite, and softening due to larger clusters. The existence of carbides on interfaces of $\mathrm{CNT} / \mathrm{Al}$ can cause higher strengthening [52].

It is very significant to have knowledge regarding the interaction between CNTs and Al due to the load transfer characteristics of this region. Weak bonding in this interphase area can be due to the wetting. Furthermore, CFs cannot usually have chemical interaction with $\mathrm{Al}$. Thus, this can result in low-strength bonding on interfaces. However, in cases exposed to high loads and thermal stresses, application of continuous fibers to induce higher strength in composite is recommended [53].

Formation of carbides on CFs surface can develop pits which can act as stress concentration and crack initiation sites which may cause fracture. Application of some carbide coatings on CFs can protect them from molten $\mathrm{Al}$ attack at high temperatures. The layer of carbide deposited on CFs 
can be $50-500 \mathrm{~nm}$ thick which depends on the CFs characteristics [54].

Experiments have shown that increasing load can result in crack growth due to coalescence of cavities oriented from the surface into the center of specimen. There are two reasons for crack initiation: 1. rupture of large particles, 2 . decohesion. Decohesion can result due to the difference of physical properties in different phases. Al has higher CTE and lower elastic modulus when compared to $\mathrm{Al}_{4} \mathrm{C}_{3}$ and $\mathrm{Al}_{2} \mathrm{O}_{3}$ which can cause high stress gradients on interfaces that could result in thermal residual stresses. Consequently, on interfaces, further dislocation density may appear. Rupture as a result of crack initiation in loading direction will occur on the surface which has higher dislocation density with the presence of higher amount of oxide $\left(\mathrm{Al}_{2} \mathrm{O}_{3}\right)$ and carbide $\left(\mathrm{Al}_{4} \mathrm{C}_{3}\right)$ particles [55].

$\mathrm{Al}_{4} \mathrm{C}_{3}$ and $\mathrm{Al}_{2} \mathrm{O}_{3}$ can form as shells during the $\mathrm{CF} / \mathrm{Al}$ reactions. $\mathrm{Al}_{4} \mathrm{C}_{3}$ particles can be either $30 \mathrm{~nm}$ or $0.6 \mu \mathrm{m}$, and $\mathrm{Al}_{2} \mathrm{O}_{3}$ particles may be as large as $1 \mu \mathrm{m} . \mathrm{Al}_{4} \mathrm{C}_{3}$ and $\mathrm{Al}_{2} \mathrm{O}_{3}$ particles are in the shape of elongated and spherical, respectively. $\mathrm{CF} / \mathrm{Al}$ can remain stable up to temperature $620^{\circ} \mathrm{C}$ [56].

The results have indicated that the formation of $\mathrm{Al}_{4} \mathrm{C}_{3}$ in $\mathrm{CF} / \mathrm{Al}$ composite deteriorates the mechanical properties and thermal conductivity. Due to the reaction between $\mathrm{CF}$ and $\mathrm{Al}$ at high temperatures $(773 \mathrm{~K}), \mathrm{Al}_{4} \mathrm{C}_{3}$ will form and the formation will continue over time which results in $\mathrm{CFs}$ damaged surface and reduction of diameter. The growth of carbide $\left(\mathrm{Al}_{4} \mathrm{C}_{3}\right)$ can occur during the infiltration and cooling process especially when the exposure time increases [57].

\section{Thermal Interlaminar Shear Stress Intensity Factor to Predict Crack Initiation Sites}

The application of Metal-Matrix Composites (MMCs) is very broad in many industries, especially aerospace and automotive. One of the most applicable MMCs in industries is aluminum matrix composite which contains carbon fiber and/or carbon nanotube. However, in manufacturing carbon fiber/aluminum composites or carbon nanotube/aluminum nanocomposites, carbon can react with molten aluminum. The results of this reaction can lead to developing carbide $\left(\mathrm{Al}_{4} \mathrm{C}_{3}\right)$ and/or aluminum oxide $\left(\mathrm{AL}_{2} \mathrm{O}_{3}\right)$ in carbon/ aluminum interfaces. Hence, on the interface of carbon/ aluminum, carbon, carbide, aluminum, and aluminum oxide could be in contact with each other. The goal of this part of the study is to develop a method to identify the crack initiation site within the carbon/aluminum composites when exposed to thermal stress. In order to achieve appropriate results in this study, the new concept of thermal interlaminar shear stress intensity factor is used. The results have shown that the probability of crack initiation on interfaces of aluminum/aluminum oxide is the highest.

The aluminum symbol is $\mathrm{Al}$ and is located in boron group. $\mathrm{Al}$ metal is soft, white, and ductile. $\mathrm{Al}$ is the most abundant metal located in crust of Earth. Al has a low density and is a corrosion-resistant metal. Due to its mechanical properties, it has been widely used in structural elements, transportation, and aerospace industries [58].
MMCs offer structural and thermal applications. These materials are nonflammable and do not outgas in vacuum environment. Furthermore, their interaction with solvents and fuels is minimum. Moreover, they have higher mechanical properties such as strength, thermal conductivity, and creep resistance when they are compared to their metal counterparts [38].

Application of CNTs in reinforcing MMC occurred in 1990s. The reason for using CNT is its excellent thermal, mechanical, and electrical properties. Nowadays, CNT is used in many applications such as supercapacitors, interconnects, nanoscale transistors, molecular vehicles, artificial muscle fibers, etc. CNT strongly interacts with aluminum to create MMC. Furthermore, experiments have proved that CNT/aluminum nanocomposite has higher electrical, thermal, and mechanical properties when compared to pure aluminum. However, the wetting angle between CNT and aluminum is $130^{\circ}-140^{\circ}$ [44].

Carbon fiber/aluminum composites offer high modulus, specific strength, and low CTE. Hence, they have been frequently used in electronics and space applications. However, it seems that developing carbide on interfaces of carbon fiber/ aluminum is a drawback. The reason is carbide acts as a brittle material. Thus, it has a deteriorating effect on interfaces which degrade the mechanical properties of carbon fiber/aluminum. Nevertheless, this composite material has many applications in automotive and aerospace industries due to its high strength-to-weight ratio and low cost [45].

The application of aluminum to manufacture MMC is very broad. Aluminum is being used in many industries such as nautical, automotive, and aeronautical due to its low weight [50].

Experiments have shown that, in manufacturing process of carbon fiber/aluminum or CNT/aluminum at around $600^{\circ} \mathrm{C}$, carbon interacts with molten aluminum. As a result of this interaction, carbide $\left(\mathrm{Al}_{4} \mathrm{C}_{3}\right)$ and/or aluminum oxide $\left(\mathrm{Al}_{2} \mathrm{O}_{3}\right)$ can be developed on interfaces. Aluminum has a lower modulus $(70 \mathrm{GPa})$ than carbide $(445 \mathrm{GPa})$ and aluminum oxide $(393 \mathrm{GPa})$. On the other hand, the CTE of aluminum $(26.5 e-61 / \mathrm{K})$ is higher than carbide $(5 e-61 / \mathrm{K})$ and aluminum oxide $(8.3 e-61 / \mathrm{K})$. Consequently, when carbon/aluminum composites are exposed to thermal stress, due to difference of physical properties between these materials, de-cohesion might occur. Due to the existence of thermal residual stresses and mismatch of CTEs between these materials, stress gradients can develop over the interfaces which could result in crack initiation [55].

As it is mentioned in the previous paragraphs, in manufacturing carbon fiber/aluminum composite or CNT/ aluminum nanocomposite, carbide and aluminum oxide may develop at temperatures around $600^{\circ} \mathrm{C}$. As a result, these materials could be in contact with each other on carbon/ aluminum interfaces.

It appears that up to this time there is no research to investigate the crack initiation sites over the carbon/aluminum interfaces while they are exposed to thermal stress. Hence, the goal in this section of the study is to develop a method to identify the crack initiation sites. In order to 
perform this evaluation, the new concept and relation of thermal interlaminar shear stress intensity factor is employed.

7.1. Problem Formulation. In 2018 [18], an equation was proposed to calculate the interlaminar shear stress (ILSs) in composites and nanocomposites. As it is obvious, ILSs can be developed on fibers/matrix interfaces due to temperature variation. This equation is indicated as follows:

$$
\text { ILSs }=\Delta \alpha \cdot \Delta T \cdot G_{\max } \cdot
$$

In equation (4), $\Delta \alpha$ is the difference between the axial coefficients of thermal expansion of contacting materials, $G_{\text {max }}$ is the maximum shear modulus between the contacting materials, and $\Delta T$ is the difference between the stress-free temperature and ambient temperature.

In this part of the study, the aim is to develop a method to identify the crack initiation site within the carbon/ aluminum composites exposed to temperature variation. Previously, it was mentioned that, due to the interaction between carbon and molten aluminum, carbide and aluminum oxide could be developed on fiber/matrix interface. Thus, carbon, aluminum, carbide, and aluminum oxide could exist over the interface of fiber/matrix. Hence, they can be in contact with each other. According to equation (4), ILSs due to the temperature variation can be calculated with having, first, the mismatch of CTEs between the two materials, second, with having the temperature variation from stress-free temperature, and, third, with maximum shear modulus between the two materials.

With using equation (4), ILSs for these four materials, carbon, aluminum, carbide, and aluminum oxide that are one by another in contact with each other, can be calculated. It seems obvious that higher ILSs can cause higher stress concentration over the interfaces and consequently can cause higher probability of crack initiation.

Additionally, with closer investigation in equation (4), it can be inferred that $\Delta T$ is the same value for all the contacting materials in this research as they are part of the carbon/aluminum composite interfaces. Thus, based on equation (4), it appears that the only factor that can cause stress concentration due to the temperature variation is the multiplication of $\Delta \alpha$ with $G_{\max }\left(\Delta \alpha \cdot G_{\max }\right)$. According to this assumption, as $\Delta \alpha \cdot G_{\max }$ increases, the chance of crack initiation and/or propagation increases. Hence, it seems that $\Delta \alpha \cdot G_{\max }$ represents thermal stress intensity factor on interfaces. As a result, this relation could be called "thermal interlaminar shear stress intensity factor" and can be shown as $\mathrm{K}_{\text {TILSs }}$. Therefore, $\mathrm{K}_{\text {TILSs }}$ is equal to $\Delta \alpha \cdot G_{\max }$ as it is shown in

$$
K_{\mathrm{TILSs}}=\Delta \alpha \cdot G_{\max } \text {. }
$$

The unit of $K_{\mathrm{TILSs}}$ is $\mathrm{N} / \mathrm{k} \cdot \mathrm{m}^{2}$ and can be used to evaluate the thermal stress intensity on interfaces of two contacting materials. In this research, the objective is to identify the crack initiation and/or propagation sites over the carbon/ aluminum interfaces. Therefore, the CTEs and shear modulus of aluminum, carbon, carbide, and aluminum oxide are required to calculate $K_{\mathrm{TILSs}}$. These values are indicated in Table 6. These data, with applying (2), can contribute to calculating the thermal stress intensity on interface of contacting materials. The highest value of $K_{\text {TILSs }}$ can represent the location with highest probability of crack initiation and/or propagation in carbon/aluminum composite exposed to thermal fatigue, thermal stress, or temperature variation. In Table 7 , the values of $K_{\mathrm{TILSs}}$ for all contacting materials on carbon/aluminum interface are indicated.

7.2. Results and Discussion. In Table 7, all the values of $K_{\text {TILSs }}$ for all the materials interacting at carbon/aluminum interfaces are indicated. The ranking of $\mathrm{K}_{\mathrm{TILSs}}$ from highest to lowest values is as follows:

(1) Aluminum interacting with $\mathrm{Al}$ oxide with $K_{\mathrm{TILSs}}=2,984,800 \mathrm{~N} / \mathrm{k} \cdot \mathrm{m}^{2}$

(2) Aluminum interacting with carbide with $K_{\text {TILSs }}=2,773,500 \mathrm{~N} / \mathrm{k} \cdot \mathrm{m}^{2}$

(3) $\mathrm{Al}$ oxide interacting with $\mathrm{CNT}$ with $K_{\text {TILSs }}=1,607,200 \mathrm{~N} / \mathrm{k} \cdot \mathrm{m}^{2}$

(4) Carbide interacting with CNT with $K_{\text {TILSs }}=838,500 \mathrm{~N} / \mathrm{k} \cdot \mathrm{m}^{2}$

(5) $\mathrm{Al}$ interacting with CNT with $K_{\mathrm{TILSs}}=728,000 \mathrm{~N} /$ $\mathrm{k} \cdot \mathrm{m}^{2}$

(6) Carbide interacting with $\mathrm{Al}$ oxide with $K_{\text {TILSs }}=541,200 \mathrm{~N} / \mathrm{k} \cdot \mathrm{m}^{2}$

The mentioned ranking of $K_{\text {TILSs }}$ for two materials in contact may also represent the ranking of stress concentration and crack initiation and/or propagation sites, since $K_{\text {TILSs }}$ represents the intensity of ILSs between contacting materials. According to these results, it appears that the location on interface between $\mathrm{Al}$ and $\mathrm{Al}$ oxide has the highest probability of crack initiation and/or propagation. On the other hand, it seems that crack initiation and/or propagation on interface between carbide and $\mathrm{Al}$ oxide is less likely to occur when compared to other contacting materials. Furthermore, it appears that the value of $K_{\text {TILSs }}$ for $\mathrm{Al}$ contacting with carbide is high. Hence, it seems that the second location of crack initiation and/or propagation is on the interface between $\mathrm{Al}$ and carbide.

Moreover, these results can show that if manufacturing process of carbon/Al composite can take place without developing aluminum oxide and carbide, the chance of crack initiation and/or propagation in carbon/Al composite exposed to thermal stress decreases. The reason is, based on the results obtained from this study, the first location with highest probability of stress concentration is $\mathrm{Al} / \mathrm{Al}$ oxide interface. Furthermore, according to the results in Table 7 , the second location with highest thermal stress intensity is on $\mathrm{Al} /$ carbide interface.

$K_{\text {TILSs }}$ of $\mathrm{Al}$ interacting with $\mathrm{Al}$ oxide and carbide are $2,984,800 \mathrm{~N} / \mathrm{k} \cdot \mathrm{m}^{2}$ and $2,773,500 \mathrm{~N} / \mathrm{k} \cdot \mathrm{m}^{2}$, respectively. By 
TABLE 6: Shear modulus and CTEs of CNT, aluminum, carbide, and aluminum oxide.

\begin{tabular}{lcccc}
\hline Materials & CNT [37] & Aluminum [59] & Carbide [60] & Aluminum oxide [61] \\
\hline Shear modulus $(\mathrm{GPa})$ & 4 & 69 & 129 & 164 \\
CTE $(1 e-6 / \mathrm{K})$ & -1.5 & 26.5 & 5 & 8.3 \\
\hline
\end{tabular}

TABLE 7: The values of $K_{\text {TILSs }}$ for two materials in contact.

Materials in contact $\mathrm{Al}$ with $\mathrm{Al}$ oxide $\mathrm{Al}$ with carbide $\mathrm{Al}$ oxide with $\mathrm{CNT} \mathrm{CNT}$ with carbide $\mathrm{CNT}$ with $\mathrm{Al}$ Carbide with $\mathrm{Al}$ oxide

\begin{tabular}{lllllll}
\hline$K_{\text {TILSs }}\left(\mathrm{N} / \mathrm{k} \cdot \mathrm{m}^{2}\right)$ & $2,984,800$ & $2,773,500$ & $1,607,200$ & 838,500 & 728,000 & 541,200
\end{tabular}

eliminating of $\mathrm{Al}$ oxide and carbide in manufacturing process, the next interacting materials with highest $K_{\text {TILSs }}$ are $\mathrm{CNT} / \mathrm{Al}$ with $K_{\mathrm{TILSs}}$ equal to $728,000 \mathrm{~N} / \mathrm{k} \cdot \mathrm{m}^{2}$. It means that, by eliminating the production of $\mathrm{Al}$ oxide and carbide in manufacturing process, the value of thermal interlaminar shear stress intensity factor decreases by $75.6 \%$ which causes high reduction in stress concentration and crack propagation on $\mathrm{CNT} / \mathrm{Al}$ interface.

\section{Summary and Concluding Remarks}

(i) In the second part of the article, with the application of mathematical method, the values of ILSs $s_{\max }$ in common UFMCs due to thermal stress are obtained and indicated in Table 3. With determination of the values of ILSs $s_{\max }$ in UFMCs, these composites are ranked based on the probability of failure due to thermal cycling exposure in this environment. It means that the UFMC which has the minimum ILSs is the safest in case of failure due to the deterioration of ILSS. On the other hand, UFMC with the highest ILSs $_{\max }$ has the highest chance of de-bonding, delamination, or fracture due to the exposure to thermal stress and/or thermal cycles. According to the mentioned method, the probability of fracture due to the exposure to thermal stress in unidirectional Sic fibers/borosilicate glass matrix composite is minimum because the ILSs $s_{\max }$ is the minimum value. Inversely, the probability of fracture in unidirectional diamond fibers/CE339 epoxy matrix composite is maximum.

(ii) In Section 4 of this research, the differences between the CTEs of fibers and matrix within the SWCNTAF and MWCNTAF at temperature range of -5 to $85^{\circ} \mathrm{C}$ are calculated. Furthermore, the ILSs over the interfaces between the fibers and matrix within the SWCNTAF and MWCNTAF at the same temperature range are derived. According to the results obtained with this calculation, it appears that the chance of crack propagation rate in axial direction and interfaces between the fibers and matrix within the SWCNTAF is higher than that within the MWCNTAF, when they are exposed to thermal cycling. This conclusion is due to the higher stress concentration within SWCNTs and AF interfaces in comparison of that within the MWCNTs and AF interfaces. (iii) In Section 5 of this study, with using analytical method and equation (4), the mismatch of CTEs and ILSs between fibers and matrix for both SWCNTAF and SWCNTE in temperature range of -5 to $85^{\circ} \mathrm{C}$ is derived. The results have shown that, for both SWCNTAF and SWCNTE, $\Delta \alpha_{\max }$ and ILSs $s_{\max }$ occur at $85^{\circ} \mathrm{C}$. Furthermore, the results have indicated that $\Delta \alpha_{\max }$ and ILSs max $_{\max }$ in SWCNTAF are $49 \%$ lower than those in SWCNTE. Additionally, $\Delta \alpha_{\text {mean }}$ in SWCNTAF is $40 \%$ lower than that in SWCNTE. Moreover, ILSs $s_{\text {mean }}$ in SWCNTAF is $44 \%$ smaller than that in SWCNTE. Thus, according to these results, it can be concluded that the probability of stress concentration, crack initiation and/or propagation, and de-bonding on interfaces between matrix and fibers in SWCNTAF is less than that in SWCNTE. Hence, thermal fatigue life of SWCNTAF could be higher than that in SWCNTE. According to this conclusion, application of SWCNTAF in many industries such as aerospace and automotive that are dealing with thermal cycling and/or thermal stress is recommended.

(iv) The research topics related to carbon composites, $\mathrm{Al}$, and CNT/Al are very broad, and in this study, only the most important topics have been covered. It seems that the topics related to the mechanical properties and damage mechanism are the most significant topics which this study also has tried to cover.

(v) Based on the results which have been obtained by this research, ILSs between the SWCNT and Al foam is higher than that between MWCNT and Al foam. Consequently, stress concentration and thermal fatigue are higher within the SWCNTAF interface when compared to MWCNTAF interface. Furthermore, ILSs between the SWCNT and epoxy is higher than that between SWCNT and AF. Therefore, thermal fatigue life of SWCNTAF could be higher than that in SWCNTE. Moreover, chemical reaction between carbon and molten aluminum can induce aluminum oxide and carbide on carbon/Al interface which can cause brittleness and stress concentration in this area. Furthermore, by new relation for thermal interlaminar shear stress intensity factor, it has been proven that interface of $\mathrm{Al}$ and $\mathrm{Al}$ oxide can induce the highest and interface of carbide and $\mathrm{Al}$ 
oxide can induce the lowest stress concentrations in the cases they are exposed to thermal stress or thermal cycling.

\section{Data Availability}

The data used to support the findings of this study are available from the corresponding author upon request.

\section{Conflicts of Interest}

The author declares no conflicts of interest.

\section{Acknowledgments}

Part of the funding of this research was provided by the Mechanical and Aerospace Engineering Department in University of Missouri, Columbia. Therefore, the author would like to thank Dr. Frank Feng, the Director of the department, and Prof. Sanjeev Khanna, the author's adviser, for their support.

\section{References}

[1] S. Lijima, "Helical microtubules of graphitic carbon," Nature, vol. 354, no. 6348, pp. 56-58, 1991.

[2] T. R. Fromy, F. K. Hanson, and T. Olsen, "The optimum dispersion of carbon nanotubes for epoxy nanocomposites: evolution of the particle size distribution by ultrasonic treatment," Journal of Nanotechnology, vol. 2012, Article ID 545930, 14 pages, 2012.

[3] J. Brown, T. Hajilounezhad, N. T. Dee, S. Kim, A. J. Hart, and M. R. Maschmann, "Delamination mechanics of carbon nanotube micropillars," ACS Applied Materials \& Interfaces, vol. 11, no. 38, pp. 35221-35227, 2019.

[4] T. Hajilounezhad, D. M. Ajiboye, and M. R. Maschmann, "Evaluating the forces generated during carbon nanotube forest growth and self-assembly," Materialia, vol. 7, Article ID 100371, 2019.

[5] T. Hajilounezhad and M. R. Maschmann, "Numerical investigation of internal forces during carbon nanotube forest self-assembly," in Proceedings of the Volume 2: Advanced Manufacturing, Pittsburgh, PA, USA, November 2018.

[6] T. Hajilounezhad, Z. A. Oraibi, R. Surya et al., "Exploration of Carbon Nanotube Forest Synthesis-Structure Relationships Using Physics-based Simulation and Machine Learning," IEEE, Piscataway, NJ, USA, 2019.

[7] A. R. Ghasemi, M. M. Mohammadi, and M. Mohandes, "The role of carbon nanofibers on thermo-mechanical properties of polymer matrix composites and their effect on reduction of residual stresses," Composites Part B: Engineering, vol. 77, pp. 519-527, 2015.

[8] A. R. Ghasemi, M. Mohammadi Fesharaki, and M. Mohandes, "Three-phase micromechanical analysis of residual stresses in reinforced fiber by carbon nanotubes," Journal of Composite Materials, vol. 51, no. 12, pp. 1783-1794, 2016.

[9] A. R. Ghasemi and M. M. Fesharaki, "Effect of carbon nanotube on cured shape of cross-ply polymer matrix nanocomposite laminates: analytical and experimental study," Iranian Polymer Journal, vol. 27, no. 12, pp. 965-977, 2018.

[10] M. Sarafrazi, M. Hamadanian, and A. R. Ghasemi, "Optimize epoxy matrix with RSM/CCD method and influence of multiwall carbon nanotube on mechanical properties of epoxy/ polyurethane," Mechanics of Materials, vol. 138, Article ID 103154, 2019.

[11] A. Rai, N. Subramanian, and A. Chattopadhyay, "Investigation of damage mechanisms in CNT nanocomposites using multiscale analysis," International Journal of Solids and Structures, vol. 120, pp. 115-124, 2017.

[12] G. V. Ramana, B. Padya, R. N. Kumar, K. V. P. Prabhakar, and P. K. Jain, "Mechanical properties of multi-walled carbon nanotube reinforced polymer nanocomposites," Indian Journal of Engineering \& Materials Science, vol. 17, pp. 331$337,2010$.

[13] J. R. I. Jayathilaka, D. D. P. D. Dehigaspitiya, S. T. Pathirana, and K. R. B. Herath, "Failure mechanisms of carbon nanotube reinforced composites," Proceedings of the Annual Sessionsof Institution of Engineers Sri Lanka (IESL), Sri Lanka, January 2016.

[14] J. G. Funk and G. F. Sykes, "The effects of simulated space environmental parameters on six commercially available composite materials," Langley Research Center Hampton, Hampton, Virginia, USA, NASA Technical Paper 2906, 1989.

[15] K.-B. Shin, C.-G. Kim, C.-S. Hong, and H.-H. Lee, "Prediction of failure thermal cycles in graphite/epoxy composite materials under simulated low earth orbit environments," Composites Part B: Engineering, vol. 31, no. 3, pp. 223-235, 2000.

[16] Y. B. Unigovski, A. Grinberg, and E. M. Gutman, "Low-cycle fatigue of the light advanced materials," Procedia Engineering, vol. 66, pp. 713-722, 2013.

[17] S. Y. Park, H. S. Choi, W. J. Choi, and H. Kwon, "Effect of vacuum thermal cyclic exposures on unidirectional carbon fiber/epoxy composites for low earth orbit space applications," Composites Part B: Engineering, vol. 43, no. 2, pp. 726-738, 2012.

[18] A. Anvari, "Thermal life of carbon structures: from the Earth to after the Titan," International Journal of Aerospace Engineering, vol. 2018, Article ID 7628614, 6 pages, 2018.

[19] Z. H. Karadeniz, "A numerical study on the thermal expansion coefficients of fiber reinforced composite materials," Thesis, Graduate School of Natural and Applied Sciences, Dokuz Eylul University, Izmir, Turkey, 2005.

[20] T. H. Nam, G. Requena, and H. P. Degischer, "Modeling and numerical computation of thermal expansion of aluminum matrix composite with densely packed SiC particles," Technische Mechanik, vol. 28, no. 3-4, pp. 259-267, 2008.

[21] T. Wenlang, Q. I. Lehua, C. Su, and J. Zhou, "Mean-field homogenization based approach to evaluate macroscopic coefficients of thermal expansion of composite materials," International Journal of Heat and Mass Transfer, vol. 102, pp. 1321-1333, 2016.

[22] A. Kelly, "Composite materials for thermal expansivity matching and high heat flux thermal management," Advances in Composite Materials and Structures, vol. 334-335, pp. 1017-1020, 2007.

[23] K. Y. G. McCullough, N. A. Fleck, and F. Ashby, "The stresslife fatigue behaviour of aluminum alloy foams," Fatigue Fracture of Engineering Materials and Structures, vol. 23, no. 3, pp. 199-208, 2000.

[24] K. Y. G. McCullough, N. A. Fleck, and M. F. Ashby, "Uniaxial stress-strain behaviour of aluminium alloy foams," Acta Materialia, vol. 47, no. 8, pp. 2323-2330, 1999.

[25] Y. Sugimura, A. Rabiei, A. G. Evans, A. M. Harte, N. A. Fleck, and N. A. Fleck, "Compression fatigue of a cellular Al alloy," Materials Science and Engineering: A, vol. 269, no. 1-2, pp. 38-48, 1999. 
[26] Y. Sugimura, J. Meyer, M. Y. He, H. Bart-Smith, J. Grenstedt, and A. G. Evans, "On the mechanical performance of closed cell Al alloy foams," Acta Materialia, vol. 45, no. 12, pp. 5245-5259, 1997.

[27] A.-M. Harte, N. A. Fleck, and M. F. Ashby, "Fatigue failure of an open cell and a closed cell aluminium alloy foam," Acta Materialia, vol. 47, no. 8, pp. 2511-2524, 1999.

[28] O. B. Olurin, N. A. Fleck, and M. F. Ashby, "Fatigue of aluminum alloy foam," in Proceedings of the IFAM Met Foam 99 Conference on Metal Foams and Porous Metal Structures, MIT Publications, Bremen, Germany, 1999.

[29] J. Banhart and W. Brinkers, "Fatigue behaviour of aluminum foams," Journal of Materials Science Letters, vol. 18, no. 8, pp. 617-619, 1999.

[30] M. Kolluri, M. Mukherjee, F. Garcia-Moreno, J. Banhart, and U. Ramamurty, "Fatigue of a laterally constrained closed cell aluminum foam," Acta Materialia, vol. 56, no. 5, pp. 11141125, 2008.

[31] C. Casavola, C. Pappalettere, and F. Renzoni, "Fatigue behaviour of aluminum foam sandwich panels," in Proceedings of the 9th Youth Symposium on Experimental Solid Mechanics, pp. 40-43, Trieste, Italy, July 2010.

[32] M. GeiBendorfer and C. Proppe, Multiscale Modeling of the Fatigue Behaviour of Real Open-Cell Aluminum Foams, vol. 10, Kaiserstr, Karlsruhe, Germany.

[33] M. Nosko, F. Simancik, and R. Florek, "The fatigue behaviour of aluminum foam," Materials and Technology, vol. 47, no. 3, pp. 295-298, 2013.

[34] I. N. Orbulov, B. Katona, and G. Szebenyi, "Fatigue properties of metal matrix syntactic foams," in Proceedings of the International Congress Center Dresden, Germany, 2014.

[35] D. K. Rajak, L. A. Kumaraswamidhas, and S. Das, "Technical overview of aluminum alloy foam," Reviews on Advanced Materials Science, vol. 48, pp. 68-86, 2017.

[36] K. Shirasu, A. Nakamura, G. Yamamoto et al., "Potential use of CNTs for production of zero thermal expansion coefficient composite materials: an experimental evaluation of axial thermal expansion coefficient of CNTs using a combination of thermal expansion and uniaxial tensile tests," Composites Part A: Applied Science and Manufacturing, vol. 95, pp. 152-160, 2017.

[37] H. G. Chae and S. Kumar, "Polymer/carbon nanotube composites-an overview," Indian Journal of Fibre \& Textile Research, vol. 31, pp. 29-40, 2006.

[38] J. V. Foltz and C. M. Blackmon, "Materials Science And Engineering An Introduction," vol. 2, pp. 903-912, John Wiley \& Sons Inc., New York, NY, USA, 1990.

[39] E. Pippel, J. Woltersdorf, M. Doktor, J. Blucher, and H. P. Degischer, "Interlayer structure of carbon fibre reinforced aluminum wires," Journal of Materials Science, vol. 35, no. 9, pp. 2279-2289, 2000.

[40] C. Durkin, "Low-cost continuous production of carbon fiberreinforced aluminum composites," Master of Science thesis, Georgia Institute of Technology, Atlanta, GA, USA, 2007.

[41] T. Laha, Y. Liu, and A. Agarwal, "Carbon nanotube reinforced aluminum nanocomposite via plasma and high velocity oxyfuel spray forming," Journal of Nanoscience and Nanotechnology, vol. 7, pp. 1-10, 2007.

[42] P. Rohatgi, B. Schultz, N. Gupta, and A. Daoud, "Solidification during casting of metal-matrix composites," ASM Handbook, vol. 15, pp. 390-397, 2008.

[43] S. R. Bakshi, D. Lahiri, and A. Agarwal, "Carbon nanotube reinforced metal matrix composites-a review," International Materials Reviews, vol. 55, no. 1, pp. 41-64, 2010.
[44] B. J. Carey, J. T. Tzeng, and S. Karna, Carbon Nanotube Aluminum Matrix Composites, Army Research Laboratory, Aberdeen Proving Ground, MD, USA, 2010.

[45] A. A. Moosa, K. K. Al-Khazraji, and O. S. Muhammed, "Tensile strength of squeeze cast carbon fibers reinforced Al-Si matrix composites," Journal of Minerals and Materials Characterization and Engineering, vol. 10, no. 2, pp. 127-141, 2011.

[46] M. Skrobian, J. Krahulec, P. Krivan, S. Profily, and Z. N. Hronom, "Recycling of carbon containing aluminum matrix composites via their re-melting," Acta Metallurgica Slovaca, vol. 20, no. 4, pp. 405-409, 2014.

[47] A. B. Elshalakany, T. A. Osman, A. Khattab, B. Azzam, and M. Zaki, "Microstructure and mechanical properties of MWCNTs reinforced A356 aluminum alloys cast nanocomposites fabricated by using a combination of rheocasting and squeeze casting techniques," Journal of Nanomaterials, vol. 2014, Article ID 386370, 14 pages, 2014.

[48] J. W. Kaczmar, K. Naplocha, and J. Morgiel, "Microstructure and strength of $\mathrm{Al}_{2} \mathrm{O}_{3}$ and carbon fiber reinforced 2024 aluminum alloy composites," Journal of Materials Engineering and Performance, vol. 23, no. 8, pp. 2801-2808, 2014.

[49] E. Akbarzadeh, "Characterization of aluminum silicon/short carbon fiber composites fabricated by novel thixomixing method," Doctorial thesis, Universitat Politecnica de Caralunya, Barcelona, Spain, 2016.

[50] D. Marini, V. Genova, F. Marra, G. Pulci, and M. Valente, "Mechanical behavior with temperatures of aluminum matrix composites with CNTs," Chemical Engineering Transactions, vol. 60, 2017.

[51] K. P. So, D. Chen, A. Kushima et al., "Dispersion of carbon nanotubes in aluminum improves radiation resistance," Nano Energy, vol. 22, pp. 319-327, 2016.

[52] S. Simoes, F. Viana, M. A. L. Reis, and M. F. Vieira, "Aluminum and nickel matrix composites reinforced by CNTs: dispersion/mixture by ultrasonication," Metals, vol. 7, no. 7, p. $279,2017$.

[53] K. Shirvanimoghaddam, S. U. Hamim, M. Karbalaei Akbari et al., "Carbon fiber reinforced metal matrix composites: fabrication processes and properties," Composites Part A: Applied Science and Manufacturing, vol. 92, pp. 70-96, 2017.

[54] J. C. Viala, M. Pernnet, F. Bosselet, and J. Bouix, "Chemical compatibility between aluminum base matrices and light refractory carbide reinforcements,"Technical report, Universite Lyon, Lyon, France.

[55] M. Besterci, O. Velgosová, J. Ivan, and T. Kvackaj, "The

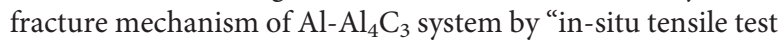
in SEM," in Proceedings of the 16th International Conference on Composite Materials, Kyoto, Japan, 2007.

[56] M. Varchola, M. Besterci, and K. Sulleiova, "Mechanical alloying Al-C system and its stability," Materials Engineering, vol. 16, no. 2, pp. 1-4, 2009.

[57] M. Lee, Y. Choi, K. Sugio, K. Matsugi, and G. Sasaki, "Effect of aluminum carbide on thermal conductivity of the unidirectional $\mathrm{CF} / \mathrm{Al}$ composites fabricated by low pressure infiltration process," Composites Science and Technology, vol. 97, pp. 1-5, 2014.

[58] N. Silvestre, "State-of-the-art review on carbon nanotube reinforced metal matrix composites," International Journal of Composite Materials, vol. 3, no. 6A, pp. 28-44, 2013.

[59] W. D. Callister, Materials Science and Engineering an Introduction, John Wiley \& Sons, Hoboken, NJ, USA, 4th edition, 1997. 
[60] T. Liao, J. Wang, and Y. Zhou, "Atomistic deformation modes and intrinsic brittleness of $\mathrm{Al}_{4} \mathrm{SiC}_{4}$ : a first-principles investigations," Physical Review B, vol. 74, no. 17, p. 174112, 2006.

[61] P. Auerkari, Mechanical and Physical Properties of Engineering Alumina Ceramics, VTT Manufacturing Technology Technical Research Center of Finland, Tampere, Finland, 1996. 